\title{
Study of inter-annual variations in surface melting over Amery Ice Shelf, East Antarctica, using space-borne scatterometer data
}

\author{
S R OzA*, R K K Singh, N K Vyas and Abhijit Sarkar \\ Space Applications Centre, Indian Space Research Organisation, Ahmedabad 380 015, India. \\ *e-mail: sandipoza@sac.isro.gov.in_sandip.r.oza@gmail.com
}

\begin{abstract}
The widespread retreat of glaciers can be considered as a response to the climate change. Being the largest retreating glacier-ice shelf system in East Antarctica, the Amery Ice Shelf-Lambert Glacier system plays an important role in contributing to sea level rise as well as the surrounding environment and climate. The present study is focused on the investigation of surface melting over the ice shelf using QuikSCAT Ku-band scatterometer data for more than 100 months covering the period from January 2000 to July 2009. The corresponding weather data of Davis Station was obtained from the website of Australian Antarctic Division. Very prominent dips in the backscatter observed in the month of January form a distinct signature caused by physical process of significant melting of the ice/snow surface. The steep increase again in February is attributed to the initiation of the freezing phenomenon. The derived melting index compared well with the passive microwave-based melting index derived by other researchers. A strong relationship was found between the scatterometer-derived melting index and the cumulative monthly mean air temperature. The highest melting was observed in the summer (January) of 2004, and thereafter gradual cooling appeared to take place in the subsequent years. The snow pack thickness, inferred from the backscatter variations, was found to be higher during winters (June) of 2004 and 2005, compared with other years.
\end{abstract}

\section{Introduction}

The Antarctic ice sheet plays an important role in the climate system (Meier 1993; Convey et al 2009). Understanding the changing mass balance and surface dynamics of Earth's major ice sheets in Greenland and Antarctica is of fundamental importance for accurate prediction of future sea level rise (Quiency and Lackman 2009). The concept of slowness of the changes over the Antarctic ice sheet has been challenged by recent satellite observations (Rignot 2006). Recent works show that much of the loss from Antarctica and Greenland is the result of the flow of ice to the ocean from ice streams and glaciers, which has accelerated over the past decade (Velicogna and Wahr 2006; Shephard and Wingham 2007). The mass balance of individual ice shelves are of great importance to the evolution of the Antarctic ice sheet as a whole and are, therefore, crucial to our understanding of sea level rise (Holland et al 2008). The continued retreat of Antarctic ice shelves has been widely attributed to recent atmospheric warming, but the available published work is not sufficient to describe how it changes in response to local and global forcing (Simonds et al 1998; Schneider et al 2006; Wingham et al 2006; Picard et al 2007; Cook and Vaughan 2009). The net indication of

Keywords. Amery Ice Shelf; Ku-band scatterometer; melting index; climate change. 
these recently published works is the pronounced regional warming over the Antarctic Peninsula that triggered the collapse of some of the ice shelves. This led to a 10-fold increase in glacier flow and rapid ice sheet retreat; East Antarctica is also not immune to changes (Rignot 2006).

The Amery Ice Shelf (AIS) (figure 1) is the third largest embayed shelf in Antarctica. Moreover, AIS is the largest ice shelf in East Antarctica and is close to the proposed site $\left(69.33^{\circ}-69.50^{\circ} \mathrm{S}, 75.92^{\circ}-\right.$ $76.50^{\circ} \mathrm{E}$ ) of the third Indian Antarctic station (http://www.ncaor.gov.in). It drains the grounded ice from the interior of the Lambert Glacier drainage basin, which covers $16 \%$ of the mass of the East Antarctic ice sheet and is the world's largest glacier by volume. The Lambert Glacier is up to $65 \mathrm{~km}$ wide and $400 \mathrm{~km}$ long, and drains about $8 \%$ of Antarctica's ice sheet to AIS. Ocean circulation under ice shelves and associated rates of melting/freezing are strongly influenced by the shape of the sub-ice-shelf cavity (Galton-Fenzi et al 2008). The geometry of the cavity beneath AIS is thought to have a strong influence on the thermohaline circulation (Williams et al 1998). Longer melt seasons and the presence of surface melt ponds on Antarctic ice shelves have been linked to shelf break-up (Scambos et al 2000). Thus, monitoring surface melt conditions is critical for evaluating the stability of Antarctic ice shelves (Kunz and Long 2006).

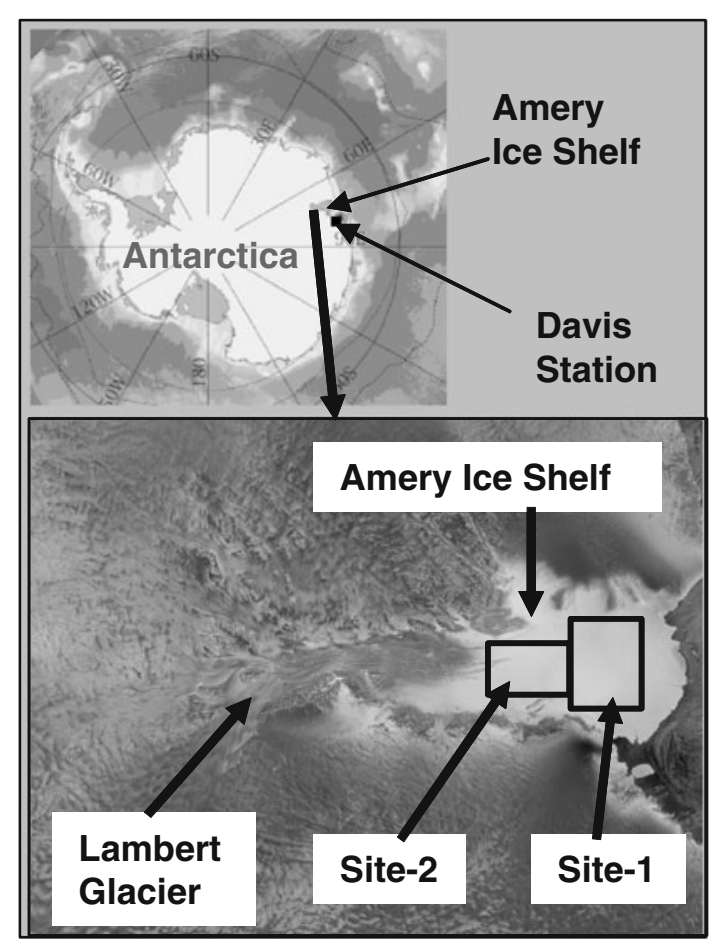

Figure 1. Study sites of Amery Ice Shelf-Lambert Glacier (AIS-LG) system (Image source: Australian Antarctic Division; website http://data.aad.gov.au).
Microwave satellite remote sensing is a practical way of monitoring long-term changes in the properties of the entire Antarctic ice sheet (Bingham and Drinkwater 2000). A number of studies have demonstrated the application of passive microwave radiometer (PMR) data in deriving the surface melt parameters such as melt/freeze onset, melt season duration and melting indices. (Zwally and Fiegles 1994; Torinesi et al 2003; Liu et al 2005; Picard and Fily 2006). Tedesco (2009) has discussed and evaluated the PMR-based melt detection algorithms and demonstrated the use of the melting index derived from the number of days for which the melting event has been observed during summer. He described that wet-snow mapping approaches can be divided into edge detection (e.g., Liu et al 2005) and threshold-based (e.g., Picard and Fily 2006) approaches.

In comparison to the PMR-based studies, the studies carried out with active microwave sensors are limited in number and much fewer for the Antarctic (Kunz and Long 2006). In the recent past, scatterometer-derived melt information have been reported and discussed in detail by Liu et al (2006), Smith et al (2003), Wang et al (2005) and Wismann (2000). These algorithms are based on the fact that the appearance of liquid water in snow decreases penetration depth and volume scattering (Ulaby et al 1986). Wismann (2000) used this reduction in backscattering as an indicator of 'melt intensity' over the Greenland ice sheet. The integrated response of backscattering in summer from the mean winter backscatter has been used as melt intensity to assess the melting of small ice caps by Smith et al (2003).

The primary objective of this study is to evaluate the surface variations observed in recent decades over AIS using QuikSCAT scatterometer data and the assessment of melting using 'temporal reduction in backscatter' (TRB) technique. The derived melting index has also been compared with the melting index derived by Picard and Fily (2006) using PMR data and with the air temperatures recorded by Australian Antarctic Station 'Davis' (figure 1).

\section{Materials and methodology}

\subsection{Materials}

Daily Browse Images of QuikSCAT Sigma-0 $(\sigma)$ measurements were obtained from the FTP site of Physical Oceanography Archive Center (ftp:// podaac.jpl.nasa.gov/pub/ocean_wind/quikscat/ sigma0browse). Daily composite global data at 0.2 degree resolution was utilised for the study. QuikSCAT has a $13.4 \mathrm{GHz}$ (Ku-band) active microwave dual-pencil-beam conically scanning 
scatterometer, with the outer beam vertically (VV) polarised and the inner beam horizontally $(\mathrm{HH})$ polarised. Hereafter, Sigma-0 for $\mathrm{HH}\left(\sigma_{\mathrm{HH}}\right)$ and Sigma-0 for VV $\left(\sigma_{\mathrm{VV}}\right)$ are referred to as $\sigma_{\mathrm{H}}$ and $\sigma_{\mathrm{V}}$, respectively for brevity. The study covers 103 months from January 2000 to July 2009. Data for the day around the middle of each month was utilised for the analysis.

The Automatic Weather Station (AWS) data was obtained from the Australian Antarctic Division website (http://data.aad.gov.au/aadc) for the Davis station near AIS. The time series data of Cumulative Melting Surface (CMS) index derived by Picard and Fily (2006) for AIS was obtained from the website http://www.lgge.obs. ujf-grenoble.fr/ picard/melting/. They derived this CMS using PMR data. CMS is defined as the sum over all the pixels of the number of melting days detected during the summer season multiplied by pixel surface area.

\subsection{Generation of time series of $\sigma$-data}

Two regions (sites) were considered for the analysis (figure 1). Site-1 covers the outer region of AIS from where ice/snow mass flows into the ocean in the form of melted water, snow mass or ice bergs. Site-2 interfaces with the glacier system that feeds the ice shelf. The number of QuikSCAT pixels within Site- 1 is 70 , and for Site- 2 it is 40 . The integrated response of these pixels within the site is expected to indicate the meso-scale effect of ice surface phenomena. The time series of site-specific $\sigma_{\mathrm{H}}$ and $\sigma_{\mathrm{V}}$ values were generated using the average statistics for both sites.

\subsection{Computation of melting indices}

The $\sigma_{\mathrm{H}}$ and $\sigma_{\mathrm{V}}$ values during summer period are lower than those during winter due to increased wetness. This fact has been utilised by Wismann (2000) and Smith et al (2003) for monitoring seasonal snowmelt over Greenland with ERS scatterometer data. A similar TRB approach has been followed in the present study by defining the Melting Index (MI) as follows:

$$
\mathrm{MI}_{\mathrm{p} n}=\sum\left(\sigma_{\mathrm{pw}}-\sigma_{\mathrm{ps} i}\right) ; \quad i=1, n
$$

Here, subscript $\mathrm{p}$ denotes the $\mathrm{H}$ - or V-polarisation. $\sigma_{\mathrm{ps} i}$ is the $\sigma$ value for the summer $i$ th month, starting from October to January. $\mathrm{MI}_{\mathrm{p} n}$ represents the MI (in $\mathrm{dB}$ ) computed for $n$th month, which is the cumulative effect of melting from the beginning of October. This implies that MI for the month of December is the cumulative TRB from October to December, and MI for the month of January is the cumulative TRB from October to January. $\sigma_{\mathrm{pw}}$ is the average $\sigma$ for the months March to September of the preceding winter. Hence, MI is temporally integrated reduction in $\sigma$, which can be taken as an indicator of the magnitude of surface melting during the spring and summer period. The cumulative mean air temperature (CMAT) is computed by integrating the monthly mean air temperatures recorded at Davis Station for the Austral summer period (December-January). The positive degreedays PDD4 was computed as the cumulative number of days with temperature greater than $4^{\circ} \mathrm{C}$. Significant melting occurs during the Austral summer period of December-January, and hence the contribution of daily air temperatures during this period to MI would be substantial. The PDD4 used in the comparison with MI of January has been computed from the beginning of December to the middle of January, because satellite data used in the study corresponds to the middle of January.

\section{Results and discussion}

\subsection{Backscatter time series}

The $\sigma_{\mathrm{H}}$ and $\sigma_{\mathrm{V}}$ time series for both sites are shown in figure 2. The distinctive feature evident from the figure is the strong negative dip during the month of January. The month of January in the Antarctic is the peak summer period and enjoys almost 24 hours daylight. The higher summer temperature affects the snow/ice surface and increases the surface melting of the snow pack.

Snow is an inhomogeneous medium consisting of ice particles, air and liquid water (if wet). The presence of liquid water in wet snow increases the permittivity of the snow layer (Ulaby et al 1986). The backscattering coefficient of wet snow is highly dependent on the snow layer wetness and roughness of the snow cover because major contribution of backscatter is caused by the air-snow interface (Fung 1994). In the case of wet snow, surface scattering dominates over volume scattering. In addition to this, the presence of liquid water in snow volume causes a dramatic increase in the dielectric loss factor of the layer, which increases the absorption coefficient and reduces the penetration depth. During the summers, the penetration depth reduces to the uppermost 3-4 cm (Liu et al 2006). This, in turn, results in decrease in $\sigma$ values. Aschcraft and Long (2006) reported that a wet snow layer of $3.8 \mathrm{~cm}$ thickness and $1 \%$ liquid moisture content results in a decrease in $\sigma$ of the order of $2.7 \mathrm{~dB}$. Hence, the reduction of about $13 \mathrm{~dB}$ in $\sigma$ from $-6 \mathrm{~dB}$ to $-19 \mathrm{~dB}$ observed in January 2004 (figure 2) is an indicator of the significant contribution from water content, which also 

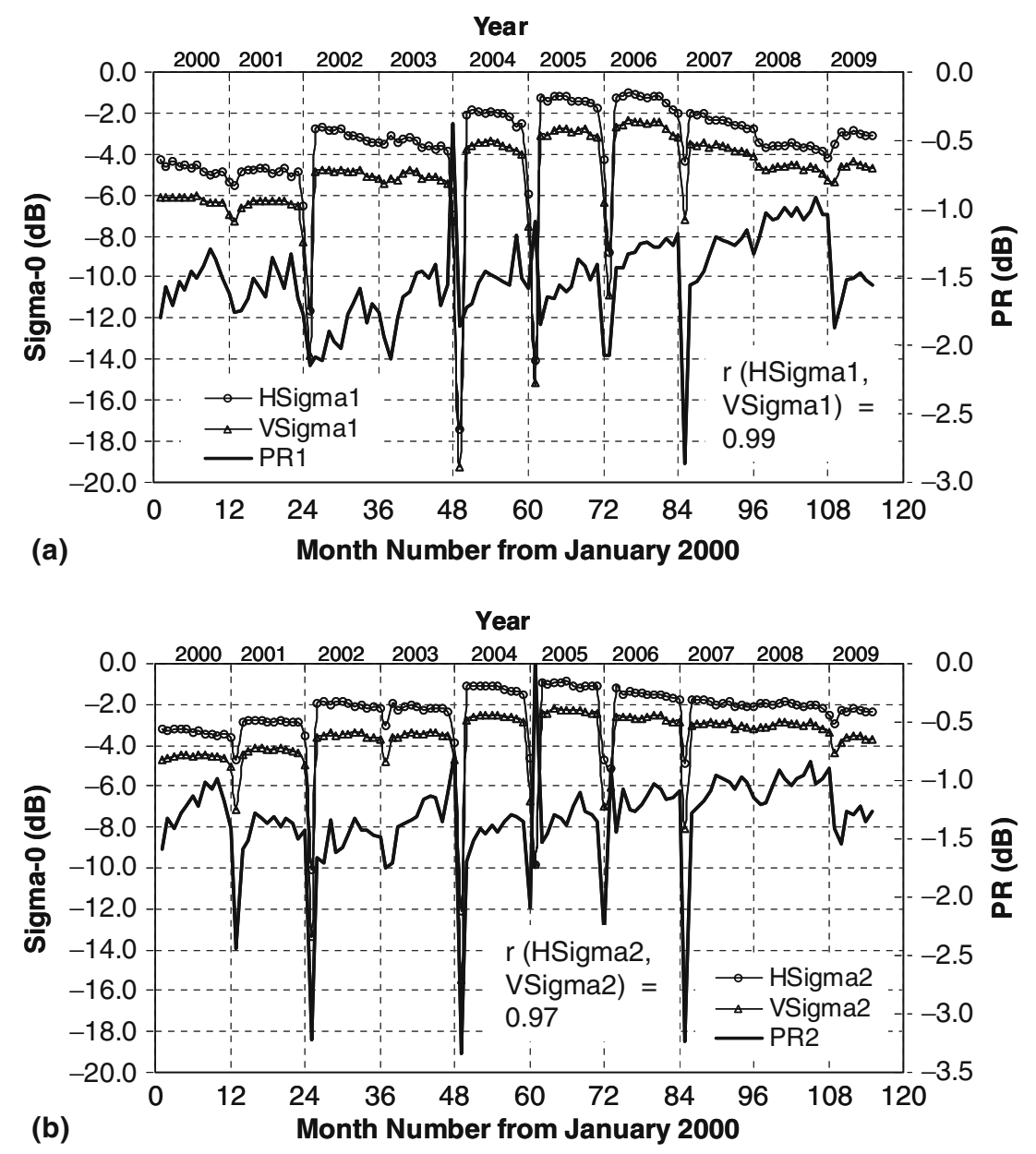

Figure 2. Time series of Ku-band backscattering coefficient $(\sigma)$ for (a) Site-1 and (b) Site-2. HSigma1 and HSigma2 represents $\sigma_{\mathrm{H}}$ values for Site-1 and Site-2, respectively, and similarly VSigma1 and VSigma2. Polarisation ratio $P R=$ $\left(\sigma_{\mathrm{V}}-\sigma_{\mathrm{H}}\right)$.

includes free melted water over surface in the form of melt streams and melt ponds.

The QuikSCAT scatterometer dual-polarisation $\sigma_{\mathrm{H}}$ and $\sigma_{\mathrm{V}}$ measurements are highly correlated but exhibit different sensitivities to the presence of liquid water (Kunz and Long 2006). This is also observed in the present study as the correlation between $\sigma_{\mathrm{H}}$ and $\sigma_{\mathrm{V}}$ measurements is 0.99 for Site-1 (figure 2a) and 0.97 for Site-2 (figure 2b). However, the 'quasi' polarisation ratio (PR), defined as $\mathrm{PR}=\left(\sigma_{\mathrm{V}}-\sigma_{\mathrm{H}}\right)$ shows significant variations during the summer months. In general, PR is $-1 \mathrm{~dB}$ and reaches up to $-3 \mathrm{~dB}$ during summer period. This is due to the greater sensitivity of H-polarised backscatter to liquid water in the snow cover than V-polarised backscatter (Kunz and Long 2006).

\subsection{Variations in melting/refreezing signatures}

It is seen that $\sigma$ during peak melting phase for Site-1 (figure 2a) is lower than that of Site-2 (figure $2 \mathrm{~b}$ ). This indicates the presence of a higher fraction of melted layer of water over Site-1 as compared with Site-2. This could be attributed to the influence of the warmer airmass reaching Site- 1 from the warmer oceanic regions. This is further supported by the findings of Liu et al (2005) that melt duration becomes shorter with increasing distance from the coastline.

The yearly backscatter profile shows an increasing trend as winter progresses. The sudden increase of $\sigma$ in February is attributed to the re-frozen melt features in the form of buried ice lenses and pipes within the snow pack (Long and Drinkwater 1994). The ice pipes and lenses have dimensions larger than or comparable to the wavelength of the radar and profoundly affect the backscatter (Liu et al 2006). Zabel et al (1995) reported that the development of ice pipes and ice lenses can increase the total equivalent surface $\sigma$ by $\sim 12 \mathrm{~dB}$. As observed in figure 2, an increase of almost $15 \mathrm{~dB}$ was observed in the month of February 2004 from that in the preceding month. If we exclude the dramatic reduction of $\sigma$ observed in peak summer, then the average annual cyclic variation 
(2000-2009) is of the order of $0.4 \mathrm{~dB}$, average of both the sites. The cyclic variations obtained by Bingham and Drinkwater (2000) using ERS scatterometer data for AIS is of the order of $0.5 \mathrm{~dB}$ during 1992-1997. The difference could be due to the frequency at which both the scatterometers have measured the variations, viz., C-band of ERS and $\mathrm{Ku}$-band of QuikSCAT.

\subsection{Inter-annual trends}

\subsubsection{Mid-winter trends of $\sigma$-data}

As observed in figure 2, the backscatter time series has an increasing trend of winter $\sigma$ up to 2005 and then decreasing up to 2009. The mid-June backscatter plot shows this distinctive pattern as observed in figure 3 . The regression summary of per-year mid-winter trends observed in $\sigma_{\mathrm{H}}$ and $\sigma_{\mathrm{V}}$ for both the sites is given in table 1 . It is evident that $R^{2}$ values are higher than $85 \%$ and $p$ values for the trend coefficients are lower than 0.05. All the coefficients are statistically significant at $95 \%$ confidence level. It is also seen that trend values are higher for Site- 1 in all cases. This could be due to the fact that Site-1 is nearer to the ice front and is affected by the warming effect from the oceanic region.

\subsubsection{Evolution of year-to-year mid-winter $\sigma$-data}

The evolution of mid-winter $\sigma_{\mathrm{H}}$ for the entire AIS is shown in figure 4. As discussed in section 3.1, the $\sigma_{\mathrm{H}}$ and $\sigma_{\mathrm{V}}$ measurements are highly correlated and show a similar pattern, and hence only the evolution of the $\sigma_{\mathrm{H}}$ measurements is discussed here. The increase in backscatter values from 2001 to 2005 and the decreasing trend from 2005 to 2009 in the majority of the pixels is evident. The microwave backscatter differs where dielectric constant $(\varepsilon)$ changes at the interfaces between air-ice and adjacent snow pack layers with different grain sizes. During the winter period, the ice sheet is covered with dry snow. The surface roughness of the dry snow layer has almost no contribution to the backscattering (Ulaby et al 1986). The backscattering coefficient increases due to the greater effect of volume scattering (the magnitude depends on the size of ice particles and the frequency used). Studies on Antarctic snow showed that the penetration depths at $\mathrm{Ku}$-band range from 5 to $12 \mathrm{~m}$ depending on the location and snow pack properties of dry snow (Arthern et al 2001). This volume of snow pack plays a major role in the backscatter during the winter period. Bingham and Drinkwater (2000) have found that these changes in

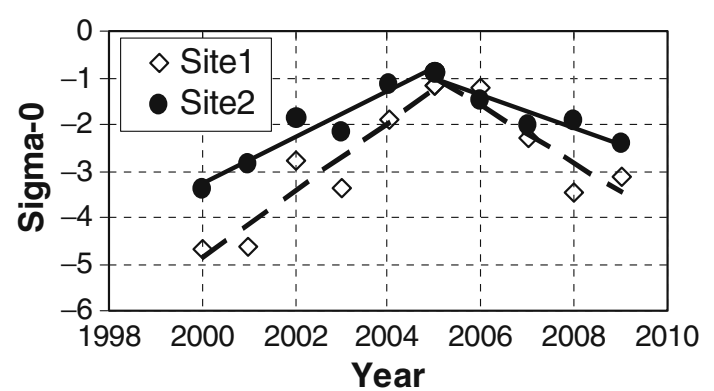

Figure 3. Inter-annual trend of $\sigma_{\mathrm{H}}$ values for the month of June (mid-winter). The dashed line represents the trend for Site- 1 and the solid line represents the trend for Site- 2 . The trends of $\sigma_{\mathrm{V}}$ are similar.

Table 1. Site-wise per year trend of mid-winter $\sigma$-data.

\begin{tabular}{lccccc}
\hline & \multicolumn{2}{c}{$\begin{array}{c}\text { Increasing trend } \\
(2000-2005)\end{array}$} & & \multicolumn{2}{c}{$\begin{array}{c}\text { Decreasing trend } \\
(2005-2009)\end{array}$} \\
\cline { 2 - 3 } & $\begin{array}{c}\text { Trend } \\
\text { Component }\end{array}$ & $\begin{array}{c}R^{2}- \\
\text { value }\end{array}$ & & $\begin{array}{c}\text { Trend } \\
(p \text {-value })\end{array}$ & $\begin{array}{c}R^{2}- \\
\text { value }\end{array}$ \\
\hline H (Site-1) & $0.72(0.005)$ & 0.88 & & $-0.61(0.028)$ & 0.84 \\
H (Site-2) & $0.50(0.002)$ & 0.93 & & $-0.35(0.012)$ & 0.91 \\
V (Site-1) & $0.73(0.002)$ & 0.92 & & $-0.58(0.025)$ & 0.85 \\
V (Site-2) & $0.47(0.001)$ & 0.96 & $-0.33(0.014)$ & 0.90 \\
\hline
\end{tabular}

backscatter are closely associated with the accumulated snow cover.

Hence, mid-winter increasing/decreasing trends observed in figure 4 could be due to the year-toyear increase/decrease in the volume of dry snow pack contributing to the scatterometer response. As discussed earlier, volume scattering dominates and the contribution from the surface is negligible for dry snow. During winter, the melted surface will re-freeze and the snow will get accumulated over the surface due to either precipitation or drift from higher-altitude regions. Wen et al (2006) have found an overall thickening trend in the Lambert-Amery Ice Shelf basin from 1992 to 2003. Hence, the higher backscatter observed during 2004 to 2005 winters could be a continuation of that trend.

\subsection{Monitoring of surface melting through scatterometer}

MIs derived from $\sigma_{\mathrm{H}}$ and $\sigma_{\mathrm{V}}$ are found to be linearly correlated with each other. Equation (2) describes the strong relationship observed between MI derived for Site- 1 from $\sigma_{\mathrm{H}}$ measurements, $\mathrm{MI}(\mathrm{H}$; Site- 1$)$, and $\sigma_{\mathrm{V}}$ measurements, $\mathrm{MI}(\mathrm{V}$; Site- 1$)$. Similarly, the relationship obtained between the MIs derived for the Site- $1, \operatorname{MI}(\mathrm{H}$; Site- 1$)$, and 


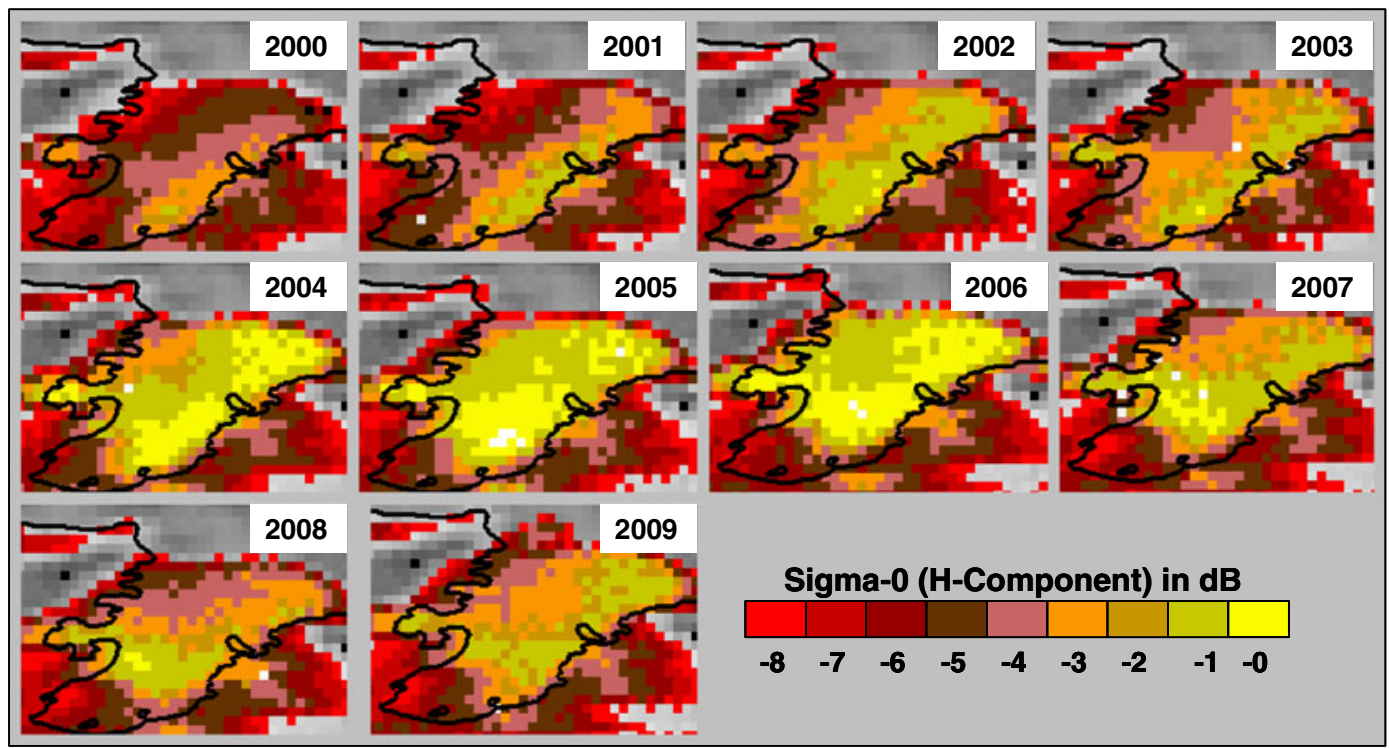

Figure 4. Evolution of mid-winter $\sigma_{\mathrm{H}}$ (June) for Amery Ice shelf. The variations in the $\sigma$ values from year-to-year may be noticed. The possible cause is the difference in volume scattering from the dry snow having different thickness year-to-year.

Site-2, $\mathrm{MI}\left(\mathrm{H}\right.$; Site-2), using $\sigma_{\mathrm{H}}$ measurements is given in equation (3).

$$
\begin{aligned}
\mathrm{MI}(\mathrm{V} ; \text { Site- } 1) & =0.9966 \times \mathrm{MI}(\mathrm{H} ; \text { Site- } 1) ; \\
R^{2} & =98 \%, \\
\mathrm{MI}(\mathrm{H} ; \text { Site- } 2) & =0.7220 \times \mathrm{MI}(\mathrm{H} ; \text { Site- } 1) ; \\
R^{2} & =95 \% .
\end{aligned}
$$

Considering these strong relationships, only one of them, namely the MI computed using $\sigma_{\mathrm{H}}$ for Site-1, has been described here in detail. The scatterometer-derived MI is also compared (figure 5a) with PMR-derived CMS (Picard and Fily 2006). As seen from the figure, year-to-year increase and decrease in both the time series closely follow each other. The relationship between these two indices has $95 \% R^{2}$-value for the common period from 2001 to 2006 . The substantial increase in the year 2004 and subsequent reduction from 2005 to 2009 indicate that the year 2004 faced the highest summer melting and that has continuously reduced from 2005 to 2009. The cooling effect has dominated after the highest melting event of 2004 . The positive and negative trends of melting during 1979-2008 with no coherent special pattern were observed by Tedesco (2009). Also, it may be noted that the smaller peak of MI for the year 2002 is in concurrence with the findings of Tedesco (2009).

The highest MI observed in 2004 is attributed to the significant melting over the surface due to increase in CMAT during the summer period (figure 5a). MI appears to be nonlinearly related to CMAT, as observed in figure 5(b). Here, we have studied the melting process and its relationship with CMAT as one of the important parameters responsible for melting. The physical nature of the
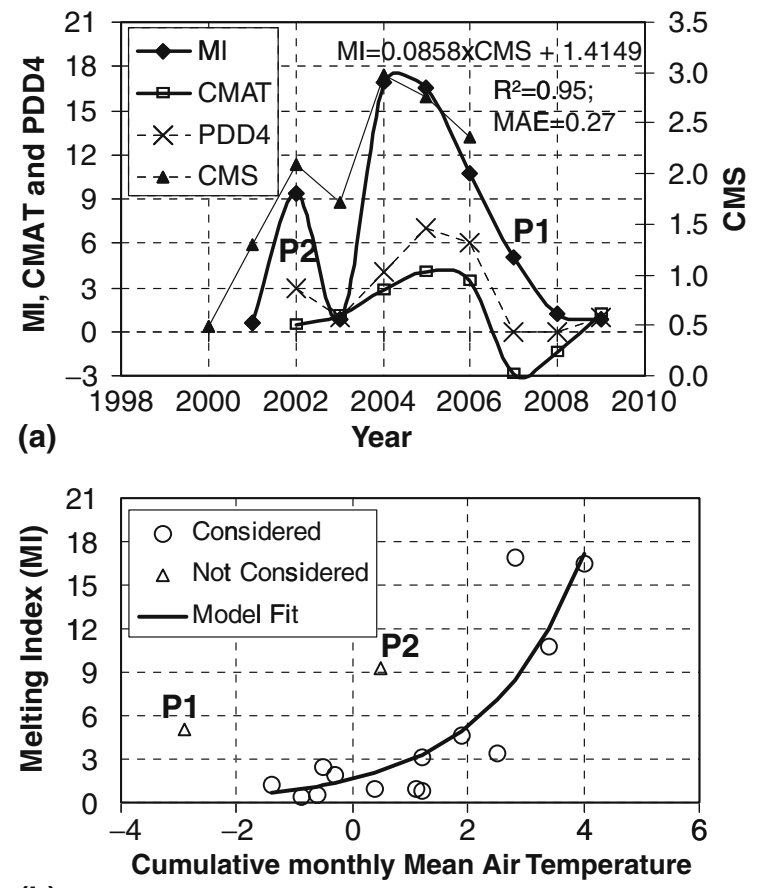

(b)

(CMAT)

Figure 5. (a) Inter-annual variations of melting index (MI), cumulative melting surface (CMS), cumulative monthly mean air temperature (CMAT) and number of positive degree days PDD4 with temperature greater than $4^{\circ} \mathrm{C}$ for the month of January; (b) inter-relationship between MI and CMAT. The points P1 and P2 are not considered in the analysis for the reasons discussed in the text.

phenomenon is such that MI should saturate on the higher (due to complete melting of surface layer of ice) and lower extreme (due to temperature falling below the melting point) of the temperature scale. 
It is observed that two of the observations, January 2002 (P1) and January 2007 (P2), are found with the MI values much higher than that is indicated by the nature of relationship. These observations were studied further to understand the likely cause behind the unusual behaviour. It is interesting to note that for MI $(=9.32)$ of P2, the PDD4 is of the order of 3 . It is also observed that all the values having $\mathrm{PDD} 4 \geq 4$ show higher MI values. Hence, the reason of relatively higher MI values of the observation P2 could be due to fewer days with high-temperature events, even though the average monthly temperature is low due to much lower temperature on other days. Still, the higher MI for $\mathrm{P} 1$ with PDD4 $=0$ needs further examination.

It is to be noted that the point measurement of air temperature may represent only a small area around the weather station and the majority of the ground area still had higher (lower) air temperature and experienced lower (higher) melting (Liu et al 2005). In addition to this, as explained by Picard et al (2007), surface melting changes are not necessarily explained by changes in temperature. This is due to the fact that surface melting depends on all the terms of the surface energy balance, which account for the local weather/cloud conditions in addition to the air temperature. Moreover, the variations in the backscatter values are also subject to the attenuation from the atmosphere.

These could be the possible reasons for the unusual behaviour of points $\mathrm{P} 1$ and $\mathrm{P} 2$. Therefore, while developing the relationship between CMAT and MI, these points were not considered in the analysis. The following relationship was found with the remaining 14 points.

$$
\mathrm{MI}=1.6133 \times \exp (0.5915 \times \mathrm{CMAT}) .
$$

The statistics found for the above relationship are $R^{2}=0.77$ and $F$-ratio $=42.37$. The mean absolute error (MAE) in MI computed with this developed relationship is of the order of $1.7 \mathrm{~dB}$. These statistics indicate the reliability of obtained relationship. Because QuikSCAT is not available from December 2009 onwards, the available data from Oceansat-II may be utilised for continuity of assessment of surface melting over ice shelves and utilisation of $\mathrm{MI}$ as an indicator in climate change studies.

\section{Conclusions}

The study highlighted the significant variations observed over the ice surface of AIS from 2000 to 2009. The study suggests that the largest surface melting phenomenon on AIS was observed in January 2004. The summer months (DecemberJanuary) of 2000-2001, 2002-2003 and 2007-2008 have faced minimum surface melting as compared with other years. The maximum snow depth during this period is observed for the winter period (June) of the years 2004 and 2005. The number of positive degree days with higher than $4^{\circ} \mathrm{C}$ air temperature is found to have significant effect on surface melting. The increasing/decreasing trends observed in the backscatter time series during the study period need further investigation in order to understand their contribution to the change in atmospheric/ocean parameters and their possible implications for climate change. This study is also important in the context of Ku-band scatterometer on board Oceansat-II, launched by India in September 2009, which is providing the coverage of both polar regions on a daily basis.

\section{Acknowledgements}

The authors are grateful to Dr R R Navalgund, SAC/ISRO, for his constant encouragement and guidance to carry out the activities in the field of polar science. The suggestions and critical review provided by Dr J S Parihar, Dr P K Pal and Dr M Chakraborty (SAC) are gratefully acknowledged. The support provided by the MOSDAC/SAC team in the compilation of required data is highly acknowledged. The authors, especially, S R Oza and R K K Singh, would like to gratefully acknowledge the Director, NCAOR, for providing opportunity to study the polar ice dynamics in Indian Scientific Expedition to Antarctica. The guidance on ice processes provided by Dr A Ganju, SASE, during the 28th expedition is deeply acknowledged. The valuable comments and suggestions provided by the Editor, JESS, and the anonymous reviewers are thankfully acknowledged.

\section{References}

Arthern R J, Wingham D J and Ridout A L 2001 Controls on ERS altimeter measurements over ice sheets: Footprint-scale topography, backscatter fluctuations, and the dependence of microwave penetration depth on satellite orientation; J. Geophys. Res. 106 33,471-33,484.

Aschcraft I S and Long D G 2006 Comparison of methods for melt detection over Greenland using active and passive microwave measurements; Int. J. Remote Sens. 27 2469-2488.

Bingham A W and Drinkwater M R 2000 Recent changes in the microwave scattering properties of the Antarctic ice sheet; IEEE Trans. Geosci. Remote Sens. 38 1810-1820.

Convey P, Bindschadler R, Prisco G D, Fahrbach E, Gutt J, Hodgson D A, Mayewski P A, Summerhayes C P, Turner $\mathrm{J}$ and The Acce Consortium 2009 Antarctic climate change and the environment; Antarct. Sci. 21 541-563.

Cook A J and Vaughan D G 2009 Overview of aerial changes of the ice shelves on the Antarctic Peninsula over the past 50 years; Cryosphere Discuss 3 579-630. 
Fung A 1994 Microwave scattering and emission models and their applications (Norwood: Artech House), p. 573.

Galton-Fenzi B K, Maraldi C, Colemanand R and Hunter J 2008 The cavity under Amery ice shelf, East Antarctica; J. Glaciol. 54 881-887.

Holland P R, Jenkins A and Holland D M 2008 The response of Ice Shelf basal melting to variations in ocean temperature; J. Climate 21 2558-2572.

Kunz L B and Long D 2006 Melt detection in Antarctic iceshelves using scatterometers and microwave radiometers; IEEE Trans. Geosci. Remote Sens. 44 2461-2469.

Liu H W, Wang L and Jezek K 2005 Wavelet-transform based edge detection approach to derivation of snowmelt onset, end and duration from satellite passive microwave measurements; Int. J. Remote Sens. 26 4639-4660.

Liu H W, Wang L and Jezek K 2006 Spatio-temporal variations of snow melt zones in Antarctic ice sheet derived from satellite SMMR and SMM/I data (1978-2004); J. Geophys. Res. 111 1-20.

Long D and Drinkwater M R 1994 Greenland observed at high resolution by the Seasat-A scatterometer; J. Glaciol. 32 213-230.

Meier M F 1993 Ice, climate and sea level: Do we know what is happening? In: NATO ASI Series, Ice in the Climate System (ed.) Pettier W R (Berlin, Germay: Springer-Verlag), pp. 141-160.

Picard C and Fily M 2006 Surface melting observations in Antarctica by microwave radiometers: Corrcting 26-year time series from changes in acquisition hours; Remote Sens. Environ. 104 325-336.

Picard G, Fily M and Gallee H 2007 Surface melting derived from microwave radiometer: A climatic indicator in Antarctica; Ann. Glaciol. 46 29-34.

Quiency D G and Lackman A 2009 Progress in satellite remote sensing of ice sheets; Prog. Phys. Geogr. 33 $547-567$.

Rignot E 2006 Changes in ice dynamics and mass balance of the Antarctic ice sheet; Phil. Trans. R. Soc. A 364 $1637-1655$.

Scambos T, Hulbe C, Fahnestock M and Bohlander J 2000 The link between climate warming and break-up of ice shelves in the Antarctic Peninsula; J. Glaciol. 46 510-530.

Schneider D P, Steig E J, Ommen T, Dixon D, Mayewski P A, Jones J and Bitz C 2006 Antarctic temperature over the past two centuries from ice cores; Geophys. Res. Lett. 33, doi: 10.1029/2006GL027057.

Shephard A and Wingham D 2007 Recent sea-level contributions of the Antarctic and Greenland icesheets; Science 315 1529-1532.
Simonds I, Jones D A and Walland D J 1998 Multi-decadal climate variability in the Antarctic region and global change; Ann. Glaciol. 27 617-622.

Smith LC, Sheng Y, Forster R R, Steffen K, Frey K E and Alsdorf D E 2003 Melting of small Arctic ice caps observed from ERS scatterometer time series; Geophys. Res. Lett. 30, doi: 10.1029/2003GL017641.

Tedesco M 2009 Assessment and development of snowmelt retrieval algorithms over Antarctica from K-band spaceborne brightness temperature (1979-2008); Remote Sens. Environ. 113 979-997.

Torinesi O, Fily M and Genthon C 2003 Interannual variability and trends of the Antarctic summer melting period from 20 years of spaceborne microwave data; J. Climate 16 1047-1060.

Ulaby F, Moore R and Fung A 1986 Microwave remote sensing, active and passive; Vol. III (Norwood: Artech House) pp. $1893-1894$.

Velicogna I and Wahr J 2006 Measurements of timevariability show mass loss in Antarctica; Science 311 $1754-1756$.

Wang L, Sharp M J, Rivard B, Marshall S and Burgess D 2005 Melt season duration on Canadian Arctic caps, 2000-2004; Geophys. Res. Lett. 32, doi: 10.1029/2005GL023962.

Wen J, Jezek K C, Monaghan A J, Sun B, Ren J and Huybrechts P 2006 Accumulation variability and mass budgets of the Lambert Glacier-Amery Ice Shelf system, East Antarctica, at high elevations; Ann. Glaciol. 43 351-360.

Williams M J M, Jenkins A and Determann J 1998 Physical control on ocean circulation beneath ice shelves revealed by numerical models. In: Ocean, ice and atmosphere interactions at the Antarctic continental margin, Antarctic Research Series 75 (eds) Jacobs S S and Weiss R R (Washington DC: American Geophysical Union), pp. 285-300.

Wingham D J, Shephard A, Muis A and Marshall G J 2006 Mass balance of Antarctic ice sheet; Phil. Trans. R. Soc. A 364 1627-1635.

Wismann V 2000 Monitoring of seasonal snowmelt on Greenland with ERS scatterometer data; IEEE Trans. Geosci. Remote Sens. 38 1821-1826.

Zabel I H, Jezek K C, Baggeroer P A and Gogineni S P 1995 Ground-based radar observations of snow stratigraphy and melt processes in the percolation facies of the Greenland ice sheet; Ann. Glaciol. 21 40-44.

Zwally H J and Fiegles S 1994 Extent and duration of Antarctic surface melting; J. Glaciol. 40 463-476. 